\title{
Künt karın travması sonrası gelişen izole jejunum perforasyonu
}

\author{
Isolated jejunal perforation following blunt abdominal trauma
}

\author{
Ahmet Pergel ${ }^{1}$, Remzi Adnan Akdoğan², İbrahim Aydın ${ }^{1}$
}

\section{ÖZET}

Künt karın travmasına bağlı izole jejunum perforasyonu oldukça nadirdir. Klinik bulgular başlangıçta genellikle spesifik olmadığından tanısı güçtür. Bu nedenle tedavisi geciken hastalarda mortalite ve morbidite riski artar. Bu tip travmalarda klasik radyolojik yöntemler tanı açısından yetersizdir. Erken tanı açısından barsak perforasyonu ihtimalinin düşünülmesi ve tekrarlayan muayeneler önemlidir. Burada künt karın travmasına bağlı izole jejunum perforasyonu gelişen 28 yaşında erkek hasta sunuldu.

Anahtar kelimeler: Künt karın travması, izole jejunum perforasyonu, erken tanı.

\section{GíRiş}

Künt karın travmasında en sik yaralanan organlardan biri jejunumdur ancak izole jejunum perforasyonu nadir (\%1) görülür ve tanısı güçtür. ${ }^{1}$ Travmanın etkisiyle karın duvarı ve vertebra arasında sık1şan ince barsak segmentinde lümen içi basıncında ani artışa bağlı olarak patlama tarzı yırtık oluşur. Günümüzde en sık sebep motorlu araç kazalarıdır. Erken dönemde klinik bulgularının belirgin olmaması ve spesifik tanı araçlarının bulunmaması nedeniyle tanı gecikmekte ve mortalite ve morbiditede artışa neden olmaktadır. ${ }^{2}$ Bu çalışmada; künt batın travmasına bağlı gelişen izole jejunum perforasyonu gelişen hastanın sunulması ve literatür eşliğinde tartışılması amaçlandı.

\section{OLGU SUNUMU}

Yirmi sekiz yaşında erkek hasta, marangoz atölyesinde çalışırken makineden firlayan tahta parçasının

\begin{abstract}
Isolated perforation of the jejunum, following blunt abdominal trauma, is extremely rare. These injuries are difficult to diagnose because initial clinical signs are frequently nonspecific and a delay in treatment increases mortality and morbidity of the patients. Conventional radiograms are often inadequate for diagnosing this subset of trauma. For an accurate and timely diagnosis, the possibility of bowel perforation and the need for repeated examinations should be kept in mind. Herein, we present a 28-year-old man with isolated jejunal perforation following blunt abdominal trauma.
\end{abstract}

Key words: Blunt abdominal trauma, isolated jejunal perforation, early diagnosis

karın bölgesine şiddetli çarpması sonucu gelişen karın ağrısı nedeni ile acil polikliniğine başvurdu. Yapılan ilk değerlendirmede göbek etrafinda travmaya bağlı yüzeysel laserasyon alanları mevcuttu (Resim 1). Vital bulgular ve laboratuvar bulguları normal sınırlar içindeydi. Batın muayenesinde üst kadranlarda minimal hassasiyet dişında patolojik bulgu yoktu. Ayakta direkt karın grafisi normaldi. Batın ultrasonografisinde proksimal ince barsak duvarında kalınlaşma saptandı. Serbest mayi yoktu. Hasta gözlem amacıyla yatırıldı ve sık aralıklarla karın muayenesi yapıld1. Takipler sırasında karın ağrısında şiddetlenme ve lökosit sayısında artış görüldü. $\mathrm{Bu}$ dönemde yapılan muayenede özellikle epigastrium ve sol üst kadranda rebaund ve hassasiyette artış saptandı. Yaklaşık 12 saat sonra hastada akut batın tanısı konularak ameliyata alınd1. Eksplorasyonda jejunumda Treitz ligamentine yaklaşık $35 \mathrm{~cm}$ mesafede $1 \mathrm{~cm}$ 'lik perforasyon saptand1. Etraf barsak anslarında lokalize fibrinli alanlar mevcuttu

\footnotetext{
${ }^{1}$ Recep Tayyip Erdoğan Üniversitesi Tip Fakültesi, Genel Cerrahi Anabilim Dall, Rize, Türkiye

${ }^{2}$ Recep Tayyip Erdoğan Üniversitesi Tıp Fakültesi, İç Hastalıkları Anabilim Dalı, Rize, Türkiye
}

Yazışma Adresi /Correspondence: Dr. Ahmet Pergel,

Recep Tayyip Erdoğan Üniversitesi Tıp Fakültesi, Genel Cerrahi AD. Rize, Türkiye Email: pergelahmet@hotmail.com

Geliş Tarihi/ Received: 02.04.2012, Kabul Tarihi/ Accepted: 24.07.2012

Copyright (C Dicle Tıp Dergisi 2012, Her hakkı saklıdır / All rights reserved 
(Resim 2). Diğer batın içi organlarda patoloji saptanmadı. Batının temiz olması nedeniyle defekt primer onarıld1. Bir adet dren konularak ameliyata son verildi. Takiplerinde herhangi bir sorun saptanmayan hasta 7. günde şifa ile taburcu edildi.

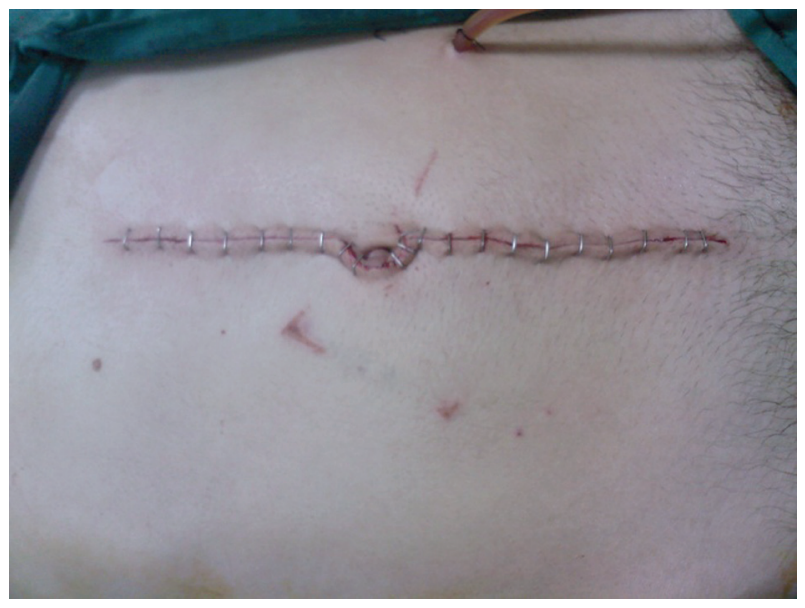

Resim 1. Göbek çevresinde travmaya bağlı laserasyon

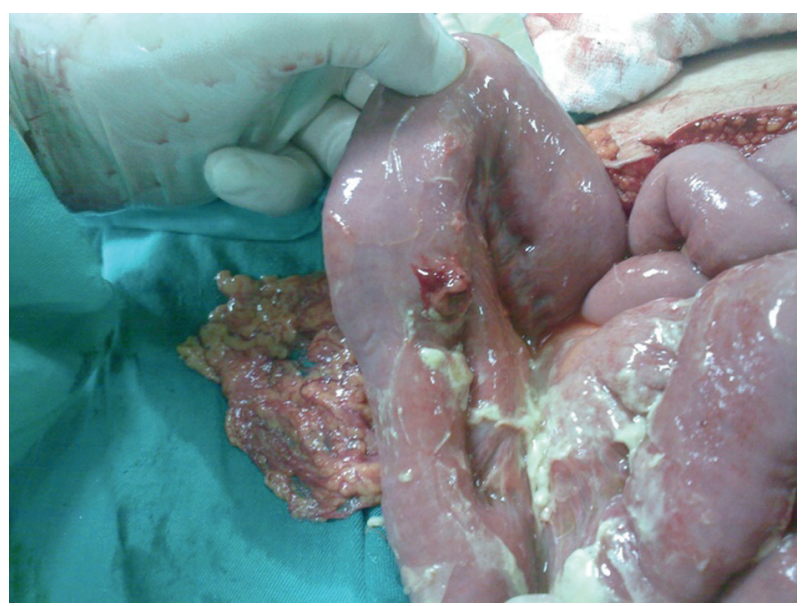

Resim 2. Jejunumda perforasyon deliği ve lokalize fibrinli alanlar

\section{TARTIŞMA}

Künt karın travmasına bağl1 en sık yaralanan üçüncü organ ince barsak olmasına rağmen izole jejunum yaralanmas1 \%1'den daha az görülür. ${ }^{1}$ Motorlu araç kazaları künt batın travmalarının \%85' ini oluşturmaktadır. Daha az sıklıkla rastlanan nedenler ise darp, iş kazaları, yüksekten düşme ve ezilmedir. ${ }^{2}$ Olgumuzda perforasyon karına çarpan tahta parçası sonucunda gelişti.
Künt karın travmasına bağlı gelişen içi boş organ yaralanmalarının erken tanısı güçtür. ${ }^{1}$ Tanıda anamnez, yaralanmanın şekli ve sık aralıklarla yapılan fizik muayene çok önemlidir.

Erken tanı için öncelikle ince barsakta yaralanma olabileceğinin düşünülmesi gerekmektedir. İçi boş organ yaralanmalarında karın muayenesinde akut batın bulguları olabilmekle birlikte, erken dönemde bulgu vermeyebilir. ${ }^{2}$ Allen ve ark. ${ }^{1}$ yaptığ 1 bir çalışmada künt batın travmalı hastalarda tek başına karın muayenesinin tanı açısından güvenirliğini \%30 olarak bildirmişlerdir. Muhtemel sebeplerinden birisi ince barsakta bakteri yoğunluğunun az olması ve peritonitin daha geç dönemde ortaya çıkmasıdır. Diğer bir neden ise travma sonrası meydana gelen iskemik hasar nedeniyle ilerleyen zamanda perforasyonun ortaya çıkmasıdır. ${ }^{3}$ Olgumuz acil kliniğe başvurduğunda genel durum iyi, karnında hafif ağrı dışında şikayeti yoktu. Muayenede batın üst kadranlarda minimal hassasiyet saptand1. Akut batını düşündürecek muayene bulguları yoktu.

Travmatik jejunum yaralanmasında klinik bulgular hafif seyredebileceğinden erken tanıda özellikle radyolojik yöntemler önem kazanmaktadır. Ayakta direk karın grafisinde diyafragma altında karakteristik olarak genellikle serbest hava bulunmaz. ${ }^{3}$ Periton lavajının (PL) intraabdominal kanamaların saptanmasında duyarlılığı yüksek olmasına rağmen, içi boş organ yaralanmalarının erken tanısında güvenilirliği düşüktür. ${ }^{4}$ İnvaziv bir girişim olduğu için komplikasyon riski taşır. Ultrasonografi batın içerisindeki az miktarda siviyı ve serbest havayı tespit etmede yeterli duyarlılıkta olmadığından erken tanıda değeri sınırlıdır. ${ }^{3}$ Bilgisayarlı tomografi (BT) künt karın travmalarında en sık kullanılan tetkiktir. Solid organlarda yaralanma olmaksızın karın içinde serbest s1vı bulunmas1 \%84,2 oranında ince barsak yaralanmasını, \%30,5 oranında da perforasyonu düşündürür. Bununla birlikte perforasyonu saptamada $\% 13$ oranında yanlış negatif bulgu verebilmektedir. ${ }^{4}$ Bilgisayarlı tomografi dikkatli yorumlandığında tanı değeri yüksek olduğu, aynı zamanda sağladığı erken tanı ile morbidite ve mortalite oranlarının düşürülmesine önemli katkıda bulunduğu bildirilmiştir. $^{3}$ Hastamızın ilk muayenesinde epigastriumda travma bölgesinde minimal hassasiyet dişında patolojik bulgu yoktu. Çekilen ayakta karın grafisinde ve laboratuvar bulgularında da patolojik bulgu 
saptanmadi. Batın ultrasonografisinde ince barsak duvarında kalınlaşma dışında patolojik bulgu yoktu. Bu bulgularla hastaya ilave tetkik ihtiyacı duyulmadı ve takip amaçlı yatırıld. Hemodinamisi stabil seyreden hastada ertesi gün akut batın bulguları gelişmesi, kan lökosit sayısında yükselme nedeniyle ön planda içi boş organ perforasyonu düşünülerek ameliyat edildi.

Künt karın travmalı bir olguda, yaşın 24'ten büyük olması ve ameliyatın gecikme süresinin 24 saatten uzun olması morbiditeyi arttıran faktörlerdir. Bunlara ilave olarak başvuru anında kan basıncının 90 mmHg'nin altında olması ve yaralanma şiddeti ölçeğinin (Injury Severity Score, ISS ) 35'in üzerinde olması durumunda ise mortalite riski $\operatorname{artar}^{5} \mathrm{Ol}$ gumuzda mortalite ve morbidite riskini arttıracak ek patolojik bulgu ve kriter yoktu. Erken tanı ve tedavi sonrası hasta şifa ile taburcu edildi.

Sonuç olarak künt batın travmasına bağlı izole jejunum perforasyonu nadir görülen ve başlangıçta çoğunlukla klinik bulgu vermediğinden erken tanısı güç olan bir yaralanmadır. Bu tür yaralanmalarda jejunum perforasyonu ihtimalini düşünmek erken tanı için çok önemlidir. Hastalar sık tekrarlanan fizik muayenelerle birlikte yakın takibe alınmalı ve gerektiğinde başta BT olmak üzere ilave tanı yöntemleri kullanılmalıdır.

\section{KAYNAKLAR}

1. Allen GS, Moore FA, Cox CS Jr, Wilson JT, Cohn JM, Duke JH. . Hollow visceral injury and blunt trauma. J Trauma 1998;45(1):69-75.

2. Munshi IA, DiRocco JD, Khachi G. Isolated jejunal perforation after blunt thoracoabdominal trauma. J Emerg Med 2006;30(4):393-5.

3. Saku M, Yoshimitsu K, Murakami J, et al. Small bowel perforation resulting from blunt abdominal trauma: interval change of radiological characteristics Radiat Med 2006;24(5):358-64.

4. Fakhry SM, Watts DD. Current diagnostic approaches lack sensitivity in the diagnosis of perforated blunt small bowel injury: analysis from 275,557 trauma admissions from the EAST multi-institutional HVI trial. J Trauma 2003;54(2):295-306.

5. Kafie F, Tominaga GT, Yoong B, Waxman K. Factors related to outcome in blunt intestinal injuries requiring operation. Am Surg 1997;63(10):889-92. 